\title{
Metodologias para obtenção de resistência e/ou tolerância da soja à ferrugem-asiática.
}

\author{
Wilmar Ferreira Lima ${ }^{1}$, Cássio Egídio Cavenaghi Prete ${ }^{1}$ Aliny Simony Ribeiro ${ }^{2}$, Marcelo Fernandes de Oliveira ${ }^{3}$, \\ Geraldo Estevam de Souza Carneiro ${ }^{3}$, Carlos Alberto Arrabal Arias ${ }^{3}$, Antonio Eduardo Pípolo ${ }^{3}$ e José Francisco \\ Ferraz de Toledo ${ }^{3}$
}

\begin{abstract}
${ }^{1}$ Professores - Universidade Estadual de Londrina, Departamento de Agronomia - Cx. Postal 6001, Londrina, PR. CEP: 86051-990. E-mail: wilmar.fl@uel.br.,cassio@uel.br. ${ }^{2}$ Pós doutorada, bolsista do CNPq, Embrapa soja. Caixa Postal 231, CEP: 86001-970, Londrina, PR. E-mail: aliny@cnpso.embrapa.br. ${ }^{3}$ Pesquisadores doutores, Embrapa Soja, Caixa Postal 231, CEP: 86001-970, Londrina, PR. E-mail: marcelo@cnpso.embrapa.br, estevam@cnpso.embrapa.br, arias@cnpso.embrapa.br, pipolo@cnpso.embrapa.br, jftoledo@uol.com.br . Autor para correspondência: Wilmar Ferreira Lima (wilmar.fl@uel.br) Data de chegada: 30/05/2011. Aceito para publicação em: 18/02/2012.

RESUMO

Lima, W.F.; Prete, C.E.C.; Ribeiro, A.S.; Toledo, J.F.F. Metodologias para obtenção de resistência e/ou tolerância da soja à ferrugem-asiática. Summa Phytopathologica, v.38, n.1, p.67-72, 2012.

Os objetivos deste trabalho foram complementar os estudos dos mecanismos genéticos da resistência e tolerância da soja à ferrugemasiática e sugerir metodologias de melhoramento que permitam o acúmulo de genes maiores e menores. Seis experimentos foram realizados durante três safras em Londrina, PR, de 2005/06 a 2007/08, envolvendo cinco parentais e as gerações derivadas $F_{2}$, $\mathrm{F}_{3}$ e $\mathrm{F}_{4}$. Foi utilizado o delineamento inteiramente casualizado, com parcelas em covas. As metodologias propostas foram planejadas para superar as dificuldades do melhorista em selecionar

genes menores na presença de genes maiores. Isto é resolvido conduzindo populações segregantes $F_{2}, F_{3}$ e $F_{4}$ numerosas para melhorar as chances de encontrar recombinações favoráveis e submetendo-as à pressão do patógeno para aumentar a frequência de genótipos resistentes/tolerantes na população $\mathrm{F}_{4}$ ou $\mathrm{F}_{5}$ quando plantas individuais serão selecionadas para formação de progênies. Consequentemente, a frequência de progênies $F_{5}$ ou $F_{6}$ superiores possuidoras de alelos nos genes menores e maiores também será aumentada.
\end{abstract}

Palavras-chave adicionais: Phakopsora pachyrhizi, Glycine Max, métodos de melhoramento, resistência à doença, melhoramento de soja.

\section{ABSTRACT}

Lima, W.F.; Prete, C.E.C.; Ribeiro, A.S.; Toledo, J.F.F. Methodologies for breeding towards resistance and/or tolerance of soybean the Asian rust. Summa Phytopathologica, v.38, n.1, p.67-72, 2012.

The objectives of this work were to complement the studies on the genetic control of soybean resistance to rust and to suggest a breeding methodology that allows the recombination and selection of soybean genotypes carrying major and minor genes for rust resistance. Six experiments were carried out in Londrina, PR during three growing seasons from 2005/06 to 2007/08 involving five parents and their derived $\mathrm{F}_{2}, \mathrm{~F}_{3}$ and $\mathrm{F}_{4}$ segregating populations. A completely randomized design was used with single plant hill-plots. The proposed methodologies ware designed to overcome the difficulties breeders face while selecting for minor gene resistance in the presence of major genes. This is dealt with by breeding large $F_{2}, F_{3}$ and $F_{4}$ segregant populations to improve the changes of the favorable gene combinations to appear and increasing genotype homozygosis under pathogen pressure to enhance the frequency of the favorable genotypes in the populations $F_{5}$ populations. This will also increase the chances of superior $F_{6}$ to appear from plant selection in the populations.

Keywords: Phakopsora pachyrhizi, Glycine Max, breeding methods, disease resistance, soybean breeding.

A soja (Glycine $\max$ (L.) Merrill) é a cultura com a maior área cultivada no Brasil. Na safra de 2010/2011 a área cultivada foi de 24,17 milhões de hectares, seguida pelo milho com 13,29 milhões de hectares e pela cana-de-açúcar com 8,03 milhões de hectares (6). O Brasil é o segundo produtor mundial de soja, sendo responsável por aproximadamente $27,7 \%$ da produção mundial (22).

A ferrugem-asiática (Phakopsora pachyrhizi Syd. e P. Syd.) foi detectada pela primeira vez no Brasil no final da safra 2000/01. Na safra 2001/02 foi relatada nas principais regiões produtoras, desde o Rio Grande do Sul até o Mato Grosso, onde nos casos mais severos, as perdas atingiram até $70 \%$ (25). Na safra seguinte espalhou-se em praticamente todas as regiões produtoras, representando uma ameaça para a cultura em função dos prejuízos causados e do aumento do custo de produção para seu controle (8).

O uso de cultivares resistentes e/ou tolerantes é o método de controle mais eficiente e barato para os produtores, além de ser o mais adequado às práticas de conservação do ambiente. Devido ao fungo Phakopsora pachyrhizi possuir diversas raças com genes múltiplos de virulência (20) e também, possuir habilidade de reter fatores de virulência desnecessários em alta frequência na população (21), a resistência vertical, conferida por genes maiores, provavelmente não será durável, mesmo quando usados em associação (piramidamento) 
(21). Como exemplo, citamos a resistência conferida pelos genes maiores Rpp1, Rpp2, Rpp3 e Rpp4 $(12,3,11,10)$ que já foi quebrada em diferentes regiões do mundo (24). No Brasil, a resistência conferida pelos genes Rpp 1 e Rpp 3 foi quebrada pelo novo isolado da ferrugemasiática proveniente do Brasil Central $(1,26)$.

A resistência horizontal, normalmente controlada por muitos genes, cada qual conferindo um pequeno efeito, é um tipo de resistência efetivo contra um número maior de raças do fungo e sua ação consiste em reduzir a taxa de desenvolvimento da doença. A detecção de resistência horizontal requer a realização de avaliações periódicas da severidade da doença, durante algumas safras (4). Por esse motivo, sua quantificação é difícil e exige um grande esforço, o que limita seu uso e faz que sejam raros os trabalhos desse tipo.

A tolerância é observada em uma situação onde uma planta é atacada por um patógeno na mesma intensidade que outras plantas, mas como resultado da infecção sofre menos danos em termos de produtividade ou qualidade do produto (18). Também, normalmente, é controlada por muitos genes e é efetiva contra um número maior de raças do fungo. A tolerância normalmente tem sido obtida por meio da avaliação da produtividade relativa de grãos, comparando parcelas de um mesmo genótipo com e sem proteção por fungicida.

Bons resultados são obtidos com a combinação de resistência horizontal e vertical (23). A literatura de resistência a doenças discute com frequência o uso alternativo da resistência horizontal e vertical. Raramente reconhece, no entanto, que os dois tipos apresentam resultados sensivelmente melhores quando usados em combinação (5).

Este trabalho teve como objetivos complementar os estudos dos mecanismos genéticos do controle da resistência/tolerância da soja à ferrugem-asiática e sugerir metodologias de melhoramento envolvendo genes maiores e menores, através dos resultados de experimentos realizados durante três anos em Londrina, Paraná.

\section{MATERIAL E MÉTODOS}

Seis experimentos foram realizados nos anos agrícolas 2005/06, 2006/07 e 2007/08, na fazenda experimental da Embrapa Soja, em Londrina, PR, localizada a $23^{\circ} 22^{\prime}$ de latitude sul. Dois experimentos foram instalados no campo em 2005/06, sendo que o primeiro foi tratado com fungicidas e semeado em 03/11/2005. O segundo não foi tratado com fungicidas e sofreu inoculações com o patógeno nas bordaduras, sendo semeado em 10/11/2005. Os genótipos parentais utilizados nos experimentos foram: BRSGO-7560 (cultivar de grupo de maturação 7.5, descendente da cultivar Abura e portadora de gene maior recessivo para resistência à ferrugem-asiática da soja, (14)); BRS 184 (cultivar de grupo de maturação 6.7, sendo portanto precoce, susceptível à ferrugem da soja); BRS 231 (cultivar de grupo de maturação 7.5 , portadora de genes menores para resistência à ferrugem (17)); BRS 232 (cultivar de grupo de maturação 7.0, susceptível à ferrugem da soja) e EMBRAPA 48 (cultivar de grupo de maturação 6.8, susceptível à ferrugem da soja). Neste ano agrícola, além dos parentais, foi utilizada a geração $F_{2}$ dos 10 cruzamentos entre eles, sem recíprocos. Os parentais foram representados por 50 repetições cada um e a geração $F_{2}$ por 120 plantas (repetições) para cada cruzamento. Cada experimento foi composto por 1.450 parcelas, em delineamento inteiramente casualizado, utilizando a metodologia de cultivo em covas $(01$ parcela $=01$ cova $=01$ planta $)$.

No ano agrícola 2006/07 os procedimentos experimentais foram semelhantes aos do ano 2005/06, inclusive as datas de semeadura.
Nesses experimentos, além dos parentais e geração $F_{2}$ foi incluída a geração $\mathrm{F}_{3}$. Os parentais foram representados por 50 repetições cada um; a geração $F_{2}$ por 160 plantas (repetições) para cada cruzamento e a geração $F_{3}$ por 40 famílias com cinco plantas cada, para cada cruzamento; totalizando 3.850 parcelas por experimento.

No ano agrícola 2007/08 dois experimentos foram instalados em campo. O primeiro foi semeado em 30/10/2007, além dos cinco parentais foi incluída a geração $\mathrm{F}_{4}$ dos 10 cruzamentos entre eles, sem recíprocos. Os parentais foram representados por 50 repetições cada um e a geração $\mathrm{F}_{4}$ de cada cruzamento por 50 famílias com três plantas cada, totalizando 1.750 parcelas. $\mathrm{O}$ segundo experimento foi semeado no dia 13/11/2007, utilizando os genótipos parentais e as gerações $F_{2}$ e $\mathrm{F}_{3}$. Os parentais foram representados por 50 repetições, a geração $\mathrm{F}_{2}$ por 160 repetições para cada cruzamento e a geração $F_{3}$ por 40 famílias com cinco plantas cada, para cada cruzamento, totalizando 3.850 parcelas. Os experimentos deste ano agrícola não foram tratados com fungicidas.

Os procedimentos experimentais como preparo do solo, adubação, controle de plantas daninhas e insetos, de todos os experimentos foram semelhantes e incluíram irrigações suplementares. A distância entre covas nas linhas úteis foi de $20 \mathrm{~cm}$ e a distância entre as linhas úteis de $1,5 \mathrm{~m}$. No intervalo entre as duas linhas úteis foram semeadas duas linhas de bordadura, utilizando uma mistura de sementes remanescentes dos genótipos em experimentação. A densidade de semeadura dessas linhas ficou próxima a 250.000 plantas.ha ${ }^{-1}$.

Foi utilizado como inóculo da ferrugem-asiática o isolado do Estado do Mato Grosso que quebrou a resistência dos genes $R p p_{1}$ e $R p p_{3}$ (26). Os procedimentos de manutenção, coleta, preparo, concentração e aplicação do inóculo estão descritos em Ribeiro et al. (17) e Pierozzi et al. (14). Nos experimentos de 2005/06 e 2006/07 foram realizadas duas inoculações. A primeira ocorreu no estádio de desenvolvimento $V_{3}(9)$ e a segunda uma semana depois. Nos experimentos de 2007/08 foi feita apenas uma inoculação no estádio de desenvolvimento $V_{5}$ ou $\mathrm{R}_{1}(9)$.

Nos experimentos tratados com fungicidas nos anos agrícolas de 2005/06 e 2006/07 foram feitas cinco aplicações, num intervalo de cerca de 15 dias entre as aplicações, sendo as duas primeiras com o fungicida Flutriafol (62,5 g i.a.ha $\left.{ }^{-1}\right)$ e as outras três com o fungicida Tebuconazole (100 g i.a.ha $\left.{ }^{-1}\right)$. Em cada ano, a primeira aplicação de fungicida foi realizada no primeiro experimento, no mesmo dia da primeira inoculação com o patógeno no segundo experimento.

As plantas foram colhidas no estágio $R_{7}(9)$, secadas a sombra, trilhadas e pesadas individualmente. As análises das médias e variâncias dos dados de produtividade de grãos dos três anos de experimentação foram calculadas utilizando o programa computacional SGQ (Sistema de Genética Quantitativa), desenvolvido no Centro Nacional de Pesquisa de Soja (Embrapa Soja). As análises estatísticas foram feitas usando o procedimento "PROC GLM" do módulo de estatística do SAS (19). A comparação entre as médias foi feita através do teste Scott-Knott a $5 \%$ de probabilidade, utilizando o programa GENES (7).

\section{RESULTADOS E DISCUSSÃO}

A Tabela 1 mostra os resultados das análises conjuntas de médias e variâncias dos parentais e das gerações $\mathrm{F}_{2}$ e $\mathrm{F}_{3}$ para a característica produtividade de grãos (g/parcela), dos anos agrícolas 2005/06, 2006/ 07 e 2007/08 experimento II (experimentos não tratados com fungicidas). Experimentos conduzidos por Ribeiro et al. (17) e Pierozzi 
et al. (14) mostraram que os genes de resistência à ferrugem-asiática possuem efeitos predominantemente aditivos e que estão dispersos nos parentais e que as interações dos efeitos dos genótipos com anos, embora significativas, são do tipo simples e não causam alterações importantes nas estimativas dos parâmetros genéticos. A análise das médias confirmou haver variabilidade entre genótipos para a característica resistência e/ou tolerância à ferrugem, observando-se a superioridade do parental BRSGO-7560, que apresenta um gene maior recessivo (resistência vertical) (14). Na sequência de melhor desempenho vem o parental BRS 231, que possui genes menores para resistência à ferrugem (resistência horizontal) (17). Os próximos melhores parentais foram a cultivar BRS 184 e a Embrapa 48 que não diferem significativamente entre si pelo teste de Scott e Knott a 5\%. A cultivar BRS 184 é o parental mais precoce e a EMBRAPA 48 é o segundo parental com maior precocidade e, portanto, podem ter atingido uma produtividade de grãos relativamente elevada devido ao menor tempo de exposição à ferrugem. Ainda observando os dados da Tabela 1 (análise conjunta de anos) constata-se que, em média, os melhores genótipos (mais produtivos) das gerações $F_{2}$ e $F_{3}$ são os originários dos cruzamentos onde a BRSGO-7560 está presente. Após os cruzamentos com a BRSGO-7560, os cruzamentos com produtividade de grãos maior, foram BRS 184 X EMBRAPA 48 e BRS 184 X BRS 231, que não diferiram entre si pelo teste de Scott e Knott a 5\%. No cruzamento BRS 184 X BRS 231, provavelmente conciliou-se a precocidade da BRS 184 com a resistência horizontal da BRS 231.

Esses dados indicam que na presença de genes maiores (BRSGO7560), o melhorista deverá encontrar dificuldades para selecionar os genótipos que também agregam, em seu genoma, os genes menores para resistência e/ou tolerância à ferrugem-asiática, conforme já relatado na literatura (13). Essa dificuldade acentua se os genes maiores mostrarem efeitos de dominância e, nesse caso, a seleção dos genótipos deverá ser postergada para gerações mais avançadas, com maior grau de homozigose. Como a resistência horizontal condicionada por genes menores pode atuar sobre fatores como período latente mais longo, número e tamanho reduzidos de lesões, número de urédias e de esporos por lesão menores e viabilidade inferior dos esporos, há provavelmente grande número de genes envolvidos $(2,14,17)$. Portanto, o programa de melhoramento deve conduzir populações $\mathrm{F}_{2}, \mathrm{~F}_{3}, \mathrm{~F}_{4}$ e $\mathrm{F}_{5}$ numerosas, em torno de 2.500 plantas por geração, para aumentar a probabilidade do aparecimento de combinações favoráveis dos genes maiores (resistência vertical) e menores (resistência horizontal) nos genótipos descendentes. O melhoramento genético combinando os dois tipos de resistência foi recomendado por Vanderplank (23) e Camargo e Bergamin Filho (5).

Uma outra estratégia de melhoramento é a avaliação de genótipos que não possuem genes maiores de resistência, sob condições de pressão de doença, selecionando os genótipos mais produtivos e cruzando eles entre si. Conduzir populações segregantes numerosas pelo método de população (bulk), sob condições de pressão da doença. Os genótipos selecionados terão maior possibilidade de possuir genes menores de resistência (resistência horizontal) e ou tolerância à ferrugem-asiática. Prosseguir no melhoramento até conseguir linhagens produtivas como as cultivares recomendadas (seleção recorrente). Posteriormente, essas linhagens poderão receber genes maiores de resistência, por retrocruzamento, obtendo assim, linhagens com a combinação de resistência horizontal e vertical, recomendadas por Vanderplank (23) e Camargo e Bergamin Filho (5).

Os dados de severidade da ferrugem-asiática desses experimentos estão publicados $(15,16)$.

As Tabelas 2 e 3 mostram os dados de média e variância de produtividade de grãos dos parentais e gerações $F_{2}, F_{3}$ e $F_{4}$ dos seus respectivos cruzamentos nos anos individuais (2005/06 a 2007/08). Por esses dados também foi possível observar a superioridade da cultivar BRSGO-7560 e dos cruzamentos onde ela participa, sendo mais evidente nos anos agrícolas 2005/06 e 2006/07, onde a pressão da doença foi maior. Nos experimentos do ano agrícola 2007/08, onde a pressão da doença foi menor, essa vantagem não foi tão evidente, sugerindo que nos experimentos onde a pressão da doença foi maior houve melhor separação entre os genótipos com resistência e/ou tolerância à ferrugem-asiática.

A Tabela 4 mostra as médias e os respectivos erros padrões dos parentais e das gerações $\mathrm{F}_{2}$ e $\mathrm{F}_{3}$ para a característica produtividade de grãos (g/parcela) dos experimentos tratados e não tratados com fungicidas, nos anos agrícolas 2005/06 e 2006/07. Os dados de média mostram variabilidade entre os genótipos analisados também na ausência da ação do patógeno, e conforme esperado, nos experimentos tratados com fungicidas os genótipos têm produtividade de grãos mais elevada. As produtividades de grãos da cultivar BRSGO-7560 foram semelhantes as das cultivares BRS 184, BRS 231 e superiores às das

Tabela 1. Médias e variâncias conjuntas de anos para a característica produtividade de grãos (g.parcela ${ }^{-1}$ ), para os parentais (quatro experimentos em três anos agrícolas, 2005/06, 2006/07, 2007/08 exp. I e 2007/08 exp. II), geração F (2005/06, 2006/07 e 2007/08 exp. II) e geração F (2006/07 e 2007/08 exp. II), experimentos não tratados com fungicidas, em Londrina, PR.

\begin{tabular}{|c|c|c|c|c|c|c|c|c|}
\hline \multicolumn{3}{|c|}{ Parentais } & \multicolumn{3}{|c|}{ Geração $F_{2}$} & \multicolumn{3}{|c|}{ Geração $F_{3}$} \\
\hline Genótipo & g/parcela ${ }^{1}$ & ${ }^{1}$ Variância & Cruzamento & g/parcela & ${ }^{1}$ Variância & Cruzamento & g/parcela ${ }^{1}$ & Variância \\
\hline BRSGO-7560 & $15,087 \mathrm{~A}$ & 36,55 & BRSGO-7560 X Embrapa 48 & $11,838 \mathrm{~A}$ & 37,39 & BRSGO-7560 X BRS 231 & $11,443 \mathrm{~A}$ & 45,71 \\
\hline BRS 231 & $10,711 \mathrm{~B}$ & 38,29 & BRSGO-7560 X BRS 231 & $11,642 \mathrm{~A}$ & 37,95 & BRSGO-7560 X BRS 232 & $11,361 \mathrm{~A}$ & 43,43 \\
\hline BRS 184 & $9,247 \mathrm{C}$ & 34,51 & BRSGO-7560 X BRS 232 & $11,514 \mathrm{~A}$ & 42,81 & BRSGO-7560 X Embrapa 48 & $11,212 \mathrm{~A}$ & 35,70 \\
\hline Embrapa 48 & $8,605 \mathrm{C}$ & 28,49 & BRSGO-7560 X BRS 184 & $10,585 \mathrm{~B}$ & 39,82 & BRSGO-7560 X BRS 184 & $10,989 \mathrm{~A}$ & 36,55 \\
\hline & & & BRS 184 X BRS 231 & $9,625 \mathrm{C}$ & 48,27 & BRS 184 X BRS 231 & $9,957 \mathrm{~B}$ & 43,79 \\
\hline & & & BRS $231 \mathrm{X}$ Embrapa 48 & $8,908 \mathrm{D}$ & 41,85 & BRS 184 X BRS 232 & $9,147 \mathrm{C}$ & 35,57 \\
\hline & & & BRS 184 X BRS 232 & $8,701 \mathrm{D}$ & 31,66 & BRS $231 \mathrm{X}$ Embrapa 48 & $9,060 \mathrm{C}$ & 35,08 \\
\hline & & & BRS 231 X BRS 232 & $8,698 \mathrm{D}$ & 29,45 & BRS 232 X Embrapa 48 & $8,937 \mathrm{C}$ & 27,58 \\
\hline & & & BRS 232 X Embrapa 48 & 7,927 E & 23,28 & BRS 231 X BRS 232 & $8,597 \mathrm{C}$ & 37,91 \\
\hline
\end{tabular}

Médias seguidas pelas mesmas letras maiúsculas na vertical, não diferem estatisticamente entre si pelo teste de Scott e Knott a 5\% de probabilidade. 
Tabela 2. Análises de média e variância para a característica produtividade de grãos (g.parcela ${ }^{-1}$ ), dos parentais e gerações $\mathrm{F}$ e $\mathrm{F}$ nos anos agrícolas 2005/2006 e 2006/07, experimentos não tratađos č̉ com fungicidas, em Londrina, PR.

\begin{tabular}{|c|c|c|c|}
\hline $\begin{array}{l}\text { Genótipos/ } \\
\text { Cruzamentos }\end{array}$ & $\begin{array}{l}\text { Número de } \\
\text { Repetições }\end{array}$ & g/parcela ${ }^{1}$ & Variância \\
\hline
\end{tabular}

(i) $2005 / 06$

\begin{tabular}{|c|c|c|c|}
\hline BRSGO-7560 & 50 & $11,300 \mathrm{~A}$ & 16,00 \\
\hline BRSGO-7560 X BRS 232 & 119 & $9,272 \quad \mathrm{~B}$ & 36,10 \\
\hline BRSGO-7560 X BRS 231 & 117 & $9,202 \quad \mathrm{~B}$ & 25,27 \\
\hline BRSGO-7560 X EMBRAPA 48 & 118 & $8,220 \mathrm{C}$ & 20,52 \\
\hline BRSGO-7560 X BRS 184 & 120 & $7,611 \mathrm{D}$ & 16,84 \\
\hline BRS 184 X BRS 231 & 119 & $7,314 \mathrm{D}$ & 25,86 \\
\hline BRS 184 X EMBRAPA 48 & 119 & $7,294 \quad \mathrm{D}$ & 16,28 \\
\hline BRS 231 & 49 & $6,753 \mathrm{E}$ & 13,15 \\
\hline BRS 231 X EMBRAPA 48 & 120 & $6,441 \quad \mathrm{E}$ & 15,19 \\
\hline BRS 231 X BRS 232 & 119 & $5,708 \quad \mathrm{~F}$ & 20,53 \\
\hline BRS 184 X BRS 232 & 118 & $5,635 \mathrm{~F}$ & 13,36 \\
\hline BRS 184 & 48 & $5,344 \quad \mathrm{G}$ & 11,59 \\
\hline BRS 232 X EMBRAPA 48 & 119 & $5,092 \mathrm{G}$ & 11,83 \\
\hline EMBRAPA 48 & 50 & $4,610 \mathrm{H}$ & 4,85 \\
\hline BRS 232 & 50 & $3,894 \mathrm{I}$ & 7,21 \\
\hline \multicolumn{4}{|c|}{ (ii) $2006 / 07$} \\
\hline BRSGO-7560 & 50 & $10,582 \mathrm{~A}$ & 14,03 \\
\hline $\mathrm{F}_{2}$ BRSGO-7560 X BRS 231 & 154 & $7,622 \mathrm{~B}$ & 13,00 \\
\hline $\mathrm{F}_{3}$ BRSGO-7560 X BRS 231 & 195 & $6,997 \quad$ B & 19,38 \\
\hline $\mathrm{F}_{2}$ BRSGO-7560 X BRS 184 & 156 & $6,352 \mathrm{C}$ & 15,16 \\
\hline $\mathrm{F}_{2}$ BRSGO-7560 X EMBRAPA 48 & 8158 & $6,229 \mathrm{C}$ & 11,20 \\
\hline $\mathrm{F}_{2}$ BRSGO-7560 X BRS 232 & 157 & $5,951 \mathrm{C}$ & 15,07 \\
\hline $\mathrm{F}_{2}$ BRS $184 \times$ BRS 231 & 158 & $5,910 \mathrm{C}$ & 12,07 \\
\hline $\mathrm{F}_{3}$ BRS $184 \mathrm{X}$ BRS 231 & 196 & $5,666 \mathrm{C}$ & 9,11 \\
\hline $\mathrm{F}_{3}$ BRSGO-7560 X BRS 232 & 194 & $5,606 \mathrm{C}$ & 13,77 \\
\hline $\mathrm{F}_{3}$ BRSGO-7560 X BRS 184 & 194 & $5,492 \mathrm{C}$ & 10,64 \\
\hline $\mathrm{F}_{3}$ BRSGO-7560 X EMBRAPA 4 & 8197 & $5,302 \mathrm{C}$ & 11,95 \\
\hline $\mathrm{F}_{2}$ BRS $231 \mathrm{X}$ BRS 232 & 158 & $5,084 \mathrm{D}$ & 9,87 \\
\hline BRS 231 & 49 & $4,900 \quad \mathrm{D}$ & 4,57 \\
\hline $\mathrm{F}_{2}$ BRS $184 \mathrm{X}$ EMBRAPA 48 & 156 & $4,549 \mathrm{D}$ & 6,54 \\
\hline $\mathrm{F}_{3}$ BRS $184 \mathrm{X}$ EMBRAPA 48 & 197 & $4,475 \quad \mathrm{D}$ & 6,20 \\
\hline $\mathrm{F}_{3} \mathrm{BRS} 231 \mathrm{X}$ BRS 232 & 199 & $4,404 \mathrm{D}$ & 8,30 \\
\hline $\mathrm{F}_{2}$ BRS $231 \mathrm{X}$ EMBRAPA 48 & 156 & $4,190 \quad \mathrm{E}$ & 7,30 \\
\hline $\mathrm{F}_{3}$ BRS $231 \mathrm{X}$ EMBRAPA 48 & 196 & $4,145 \quad E$ & 5,70 \\
\hline BRS 184 & 49 & $3,912 \mathrm{E}$ & 3,54 \\
\hline $\mathrm{F}_{3}$ BRS $184 \times$ BRS 232 & 193 & $3,896 \mathrm{E}$ & 7,97 \\
\hline $\mathrm{F}_{2}$ BRS $184 \times$ BRS 232 & 157 & $3,885 \quad \mathrm{E}$ & 6,98 \\
\hline $\mathrm{F}_{3}$ BRS $232 \mathrm{X}$ EMBRAPA 48 & 198 & $3,332 \mathrm{~F}$ & 5,05 \\
\hline $\mathrm{F}_{2}$ BRS $232 \mathrm{X}$ EMBRAPA 48 & 157 & $3,316 \quad \mathrm{~F}$ & 4,20 \\
\hline BRS 232 & 50 & $2,864 \quad \mathrm{~F}$ & 5,17 \\
\hline EMBRAPA 48 & 48 & $2,613 \mathrm{~F}$ & 1,45 \\
\hline
\end{tabular}

\footnotetext{
${ }^{1}$ Médias seguidas pelas mesmas letras maiúsculas na vertical, não diferem estatisticamente entre si pelo teste de Scott e Knott a 5\% de probabilidade no mesmo ano agrícola.
}

Tabela 3. Análises de média e variância para a característica produtividade de grãos (g.parcela ${ }^{-1}$ ), para os parentais e geração $\mathrm{F}$ no ano agrícola 2007/ 2008 (experimento I) e para os parentais e gerações ${ }^{4} \mathrm{~F}$ e $\mathrm{F}$ no ano agrícola 2007/08 (experimento II), experimentos não tratados com fungicidas, em Londrina, PR.

\begin{tabular}{llll}
\hline Genótipos/ & Número de & g/parcela $^{1}$ & Variância \\
Cruzamentos & Repetições & . & \\
\hline
\end{tabular}

(i) 2007/08 Experimento I

$\begin{array}{lllll}\text { BRSGO-7560 } & 48 & 21,325 & \text { A } & 84,34 \\ \text { BRS 231 } & 50 & 14,760 & \text { B } & 62,39 \\ \text { BRS } 184 & 49 & 13,604 & \text { B } & 69,01 \\ \text { BRSGO-7560 X BRS 231 } & 145 & 13,253 & \text { B } & 72,58 \\ \text { BRSGO-7560 X EMBRAPA 48 } & 143 & 12,671 & \text { B } & 70,21 \\ \text { EMBRAPA 48 } & 48 & 12,465 & \text { B } & 54,68 \\ \text { BRSGO-7560 X BRS 184 } & 148 & 12,429 & \text { B } & 79,63 \\ \text { BRS 184 X EMBRAPA 48 } & 147 & 12,022 & \text { B } & 82,56 \\ \text { BRS 184 X BRS 232 } & 146 & 11,666 & \text { C } & 66,13 \\ \text { BRSGO-7560 X BRS 232 } & 147 & 11,533 & \text { C } & 74,70 \\ \text { BRS 232 X EMBRAPA 48 } & 146 & 10,662 & \text { C } & 56,84 \\ \text { BRS 184 X BRS 231 } & 141 & 10,522 & \text { C } & 64,05 \\ \text { BRS 232 } & 49 & 10,312 & \text { C } & 42,11 \\ \text { BRS 231 X EMBRAPA 48 } & 143 & 10,276 & \text { C } & 75,45 \\ \text { BRS 231 X BRS 232 } & 139 & 9,025 & \text { C } & 51,13\end{array}$

(ii) 2007/08 Experimento II

\begin{tabular}{lllll}
$\mathrm{F}_{2}$ BRSGO-7560 X EMBRAPA 48158 & 20,148 & $\mathrm{~A}$ & 76,16 \\
$\mathrm{~F}_{2}$ BRSGO-7560 X BRS 232 & 159 & 18,684 & $\mathrm{~A}$ & 75,21 \\
$\mathrm{~F}_{2}$ BRS 184 X EMBRAPA 48 & 155 & 17,596 & $\mathrm{~B}$ & 63,93 \\
BRSGO-7560 & 50 & 17,390 & $\mathrm{~B}$ & 33,78 \\
$\mathrm{~F}_{2}$ BRSGO-7560 X BRS 231 & 159 & 17,331 & $\mathrm{~B}$ & 71,41 \\
$\mathrm{~F}_{2}$ BRSGO-7560 X BRS 184 & 154 & 17,190 & $\mathrm{~B}$ & 82,67 \\
$\mathrm{~F}_{3}$ BRSGO-7560 X EMBRAPA 48157 & 17,123 & $\mathrm{~B}$ & 59,45 \\
$\mathrm{~F}_{3}$ BRSGO-7560 X BRS 232 & 197 & 17,027 & $\mathrm{~B}$ & 72,63 \\
$\mathrm{~F}_{3}$ BRSGO-7560 X BRS 184 & 196 & 16,430 & $\mathrm{~B}$ & 62,19 \\
BRS 231 & 49 & 16,349 & $\mathrm{~B}$ & 72,53 \\
$\mathrm{~F}_{3}$ BRS 184 X EMBRAPA 48 & 190 & 15,904 & $\mathrm{~B}$ & 63,04 \\
$\mathrm{~F}_{3}$ BRSGO-7560 X BRS 231 & 197 & 15,844 & $\mathrm{~B}$ & 71,91 \\
$\mathrm{~F}_{2}$ BRS 184 X BRS 232 & 157 & 15,822 & $\mathrm{~B}$ & 70,05 \\
$\mathrm{~F}_{2}$ BRS 231 X EMBRAPA 48 & 157 & 15,483 & $\mathrm{C}$ & 96,52 \\
$\mathrm{~F}_{2}$ BRS 184 X BRS 231 & 154 & 15,223 & $\mathrm{C}$ & 102,7 \\
$\mathrm{~F}_{2}$ BRS 232 X EMBRAPA 48 & 154 & 14,820 & $\mathrm{C}$ & 51,56 \\
$\mathrm{~F}_{2}$ BRS 231 X BRS 232 & 155 & 14,675 & $\mathrm{C}$ & 82,04 \\
EMBRAPA 48 & 50 & 14,648 & $\mathrm{C}$ & 52,95 \\
$\mathrm{~F}_{3}$ BRS 232 X EMBRAPA 48 & 196 & 14,598 & $\mathrm{C}$ & 50,34 \\
$\mathrm{~F}_{3}$ BRS 184 X BRS 231 & 189 & 14,406 & $\mathrm{C}$ & 79,94 \\
$\mathrm{~F}_{3}$ BRS 184 X BRS 232 & 195 & 14,345 & $\mathrm{C}$ & 62,88 \\
BRS 184 & 48 & 14,148 & $\mathrm{C}$ & 53,83 \\
$\mathrm{~F}_{3}$ BRS 231 X EMBRAPA 48 & 198 & 13,925 & $\mathrm{C}$ & 64,16 \\
$\mathrm{~F}_{3}$ BRS 231 X BRS 232 & 191 & 12,967 & $\mathrm{D}$ & 68,76 \\
BRS 232 & 49 & 10,953 & $\mathrm{D}$ & 53,60 \\
\hline
\end{tabular}

\footnotetext{
Médias seguidas pelas mesmas letras maiúsculas na vertical, não diferem estatisticamente entre si pelo teste de Scott e Knott a 5\% de probabilidade no mesmo experimento.
} 
Tabela 4. Redução na produtividade de grãos comparando peso (g.parcela ${ }^{-1}$ ) de parcela sem fungicida (A) e peso de parcela com fungicida (B), dos parentais e geração $\mathrm{F}_{2}$ nos anos agrícolas 2005/2006 e 2006/2007, e geração $\mathrm{F}_{3}$ no ano agrícola 2006/2007, em Londrina, PR.

\begin{tabular}{|c|c|c|c|c|c|c|}
\hline \multirow{2}{*}{ Genótipo/Cruzamento } & \multicolumn{3}{|c|}{ Ano Agrícola 2005/2006 } & \multicolumn{3}{|c|}{ Ano Agrícola 2006/2007 } \\
\hline & $\begin{array}{c}\text { Peso S/ } \\
\text { Fung. (A) }\end{array}$ & $\begin{array}{c}\text { Peso C/ } \\
\text { Fung. (B) } \\
\end{array}$ & $\mathbf{A} / \mathbf{B}$ & $\begin{array}{c}\text { Peso S/ } \\
\text { Fung. (A) }\end{array}$ & $\begin{array}{c}\text { Peso C/ } \\
\text { Fung. (B) }\end{array}$ & $\mathbf{A} / \mathbf{B}$ \\
\hline BRS 184 & $5,34 \pm 0,49$ & $33,70 \pm 1,89$ & 0,16 & $3,91 \pm 0,27$ & $25,57 \pm 1,28$ & 0,15 \\
\hline BRS 231 & $6,75 \pm 0,52$ & $37,96 \pm 1,95$ & 0,18 & $4,90 \pm 0,31$ & $31,18 \pm 1,38$ & 0,16 \\
\hline BRS 232 & $3,89 \pm 0,38$ & $24,09 \pm 1,60$ & 0,16 & $2,86 \pm 0,32$ & $15,09 \pm 0,76$ & 0,19 \\
\hline $\mathrm{F}_{2}$ BRSGO-7560 X BRS 184F $\mathrm{F}_{3}$ BRSGO-7560 X BRS 184 & $7,61 \pm 0,38$ & $32,74 \pm 1,23$ & 0,23 & $6,35 \pm 0,315,47 \pm 0,23$ & $33,69 \pm 1,0224,74 \pm 0,83$ & $0,190,22$ \\
\hline $\mathrm{F}_{2}$ BRSGO-7560 X BRS $231 \mathrm{~F}_{3}$ BRSGO-7560 X BRS 231 & $9,20 \pm 0,47$ & $34,50 \pm 1,19$ & 0,27 & $7,62 \pm 0,296,80 \pm 0,31$ & $33,35 \pm 1,0130,09 \pm 0,96$ & $0,230,23$ \\
\hline $\mathrm{F}_{2}$ BRSGO-7560 X BRS $232 \mathrm{~F}_{3}$ BRSGO-7560 X BRS 232 & $9,27 \pm 0,55$ & $38,09 \pm 1,46$ & 0,24 & $5,95 \pm 0,315,61 \pm 0,27$ & $28,81 \pm 0,9827,51 \pm 0,91$ & $0,210,20$ \\
\hline $\mathrm{F}_{2}$ BRSGO-7560 X EMBRAPA $48 \mathrm{~F}_{3}$ BRSGO-7560 X EMBRAPA 48 & $8,22 \pm 0,42$ & $36,60 \pm 1,44$ & 0,23 & $6,23 \pm 0,275,30 \pm 0,25$ & $26,48 \pm 0,8024,54 \pm 0,77$ & $0,240,22$ \\
\hline $\mathrm{F}_{2}$ BRS $184 \mathrm{X}$ BRS $231 \mathrm{~F}_{3} \mathrm{BRS} 184 \mathrm{X}$ BRS 231 & $7,31 \pm 0,47$ & $39,80 \pm 1,62$ & 0,18 & $5,91 \pm 0,285,64 \pm 0,22$ & $37,15 \pm 1,2331,91 \pm 1,05$ & $0,160,18$ \\
\hline $\mathrm{F}_{2}$ BRS $231 \mathrm{X}$ EMBRAPA $48 \mathrm{~F}_{3}$ BRS $231 \mathrm{X}$ EMBRAPA 48 & $6,44 \pm 0,36$ & $37,77 \pm 1,57$ & 0,17 & $4,19 \pm 0,224,13 \pm 0,17$ & $28,66 \pm 1,0626,16 \pm 0,93$ & $0,150,16$ \\
\hline $\mathrm{F}_{2}$ BRS $232 \mathrm{X}$ EMBRAPA $48 \mathrm{~F}_{3}$ BRS $232 \mathrm{X}$ EMBRAPA 48 & $5,09 \pm 0,32$ & $28,62 \pm 1,17$ & 0,18 & $3,32 \pm 0,163,33 \pm 0,16$ & $22,48 \pm 0,7318,47 \pm 0,60$ & $0,150,18$ \\
\hline
\end{tabular}

cultivares BRS 232 e Embrapa 48. Observou-se que, além de ser o parental mais produtivo, a cultivar BRS 231 teve participação como parental nos cruzamentos mais produtivos.

Ainda na Tabela 4, a comparação das produtividades de grãos dos experimentos inoculados com o patógeno e sem controle da ferrugem com fungicidas, com a dos experimentos tratados com fungicidas, nos anos agrícolas 2005/2006 e 2006/2007, observa-se que o parental BRSGO-7560 é o que possui a maior "resistência e/ou tolerância" à ferrugem, pois sofreu a menor redução de produtividade de grãos. Os cruzamentos em que a BRSGO-7560 participou também foram os que sofreram menores reduções de produtividade nas gerações $F_{2}$ e $F_{3}$. Portanto, quando se usa a metodologia de parcela tratada e não tratada, sob pressão de ferrugem, para selecionar cultivares com genes menores para resistência e/ou tolerância à ferrugem-asiática, se genes maiores estiverem presente, estes poderão dificultar a seleção pelo melhorista dos genótipos possuidores de genes menores. Esta constatação está de acordo com o que foi observado por Parlevliet (13), o qual afirma que a seleção para resistência parcial ou horizontal, na presença de genes maiores para resistência (resistência vertical), pode ser ineficaz, uma vez que o efeito dos genes maiores dificulta a detecção dos efeitos dos genes menores.

No entanto, os dados mostram consistência de aumento de resistência e/ou tolerância à ferrugem. Na Tabela 4, observa-se que as gerações $\mathrm{F}_{2}$ e $\mathrm{F}_{3}$ do cruzamento entre BRSGO-7560 e BRS 231 foram os que sofreram menores reduções de produtividade de grãos nas condições dos experimentos não tratados e tratados com fungicidas. Como esta metodologia de comparação de experimentos tratados e não tratados é trabalhosa, pode-se propor a seleção pela produtividade de grãos sob pressão do patógeno, conforme recomendada por Tschanz e Wang (21). Selecionar apenas pela produtividade de grãos, torna o método de fácil aplicação prática em relação às avaliações de severidade, esporulação, entre outras, extremamente trabalhosas.

Uma possível solução para se agregar os efeitos dos genes maiores e menores nos genótipos dos programas de melhoramento para resistência à ferrugem seria avançar populações segregantes numerosas sob pressão do patógeno para contar com apoio da seleção "natural" e postergar a seleção até a geração $\mathrm{F}_{4}$ ou $\mathrm{F}_{5}$, onde os genótipos estarão mais fixados. Esse procedimento provavelmente anularia o problema de confundimento dos efeitos de genes maiores e menores nas seleções realizadas pelos melhoristas em plantas individuais das gerações iniciais do programa. Essa estratégia está sendo utilizada no programa de melhoramento genético de soja para resistência e/ou tolerância à ferrugem da Embrapa Soja. Progênies $F_{5}$ descendentes de populações segregantes $\left(\mathrm{F}_{2}, \mathrm{~F}_{3}\right.$ e $\left.\mathrm{F}_{4}\right)$ têm demonstrado resistência e/ou tolerância à ferrugem em campo experimental, sob pressão do fungo $P$. pachyrhizi inoculado, superiores às das progênies portadoras de genes maiores e desenvolvidas sem pressão do patógeno.

\section{AGRADECIMENTOS}

Os autores agradecem à FINEP e ao $\mathrm{CNPq}$ pelo financiamento parcial da pesquisa e pela bolsa de produtividade e pesquisa do terceiro autor.

\section{REFERÊNCIAS BIBLIOGRÁFICAS}

1. Arias, C.A.A.; Ribeiro, A.S.; Yorinori, J.T.; Brogin, R.L.; Oliveira, M.F.; Toledo, J.F.F. Inheritance of resistance of soybean to rust (Phakopsora pachyrhizi Sidow). In: Moscardi et al. (EDs.). World Soybean Research Conference, 7; International Soybean Processing and Utilization Conference, 4; Congresso Brasileiro de Soja, 3, 2004, Foz do Iguassu. Abstracts of contribuited papers and posters. Londrina: Embrapa soybean, 2004. p. 100. (Embrapa Soja. Documentos,228).

2. Arias, C.A.A.; Toledo, J.F.F.; Almeida, L.A.; Pípolo, A.E.; Carneiro, G.E.S.; Abdelnoor, R.V.; Rachid, B.F.; Ribeiro, A.S. Asian rust in Brazil: varietal resistance. In: Kudo et al. (Ed.). Facing the challenge of soybean rust in South America. Tsukuba: JIRCAS; Londrina: Embrapa Soybean, 2008. p. 29-30. (JIRCAS Working Report, 58) 
3. Bromfield, K.R.; Hartwig, E.E. Resistance to soybean rust and mode of inheritance. Crop Science, Madison, v.20, n.2, p. 254255, 1980 .

4. Bromfield, K.R. Soybean rust. Monography No 11. St. Paul: American Phytopathological Society Press, MN. 1984. 65 p.

5. Camargo, L.E.; Bergamin Filho, A. Controle Genético. In: Bergamin Filho et al. (Eds.). Manual de fitopatologia, 3. Ed., São Paulo: Agronômica Ceres, 1995. v.1, cap. 37, p. 729-760.

6. Companhia Nacional de Abastecimento. Séries históricas de área, produtividade e produção de grãos. Brasília, Disponível em: <http://www.conab.gov.br/conteudos.php? $\mathrm{a}=1253 \& \mathrm{t}=>$. Acesso em: 19 abril 2011.

7. Cruz, C.D. Programa GENES: versão Windows, aplicativo computacional em genética e estatística. Viçosa, MG, UFV, 2001. 648 p.

8. EMBRAPA - Centro Nacional de Pesquisa de Soja. In: Tecnologias de produção de soja - Paraná 2007. Londrina, 2006.

9. Fehr, W.R.; Caviness, C.E.; Burmood, D.T.; Pennington, J.S. Stage of development descriptions for soybeans, Glycine $\max (\mathrm{L}$. Merril. Crop Science, Madison, v.11, n.6, p. 929-931, 1971.

10. Hartwig, E.E. Identification of a fourth major gene conferring resistance to soybean rust. Crop Science, Madison, v.26, n.6, p. $1135-1136,1986$

11. Hartwig, E.E.; Bromfield, K.R. Relationships among three genes conferring specific resistance to rust in soybeans. Crop Science, Madison, v.23, n.2, p. 237-239, 1983.

12. Mclean, R.J.; Byth, D.E. Inheritance of resistance to rust (Phakopsora pachyrhizi) in soybeans. Australian Journal Agricultural Research, Collingwood, v. 31, p. 951-956, 1980.

13. Parlevliet, J.E. Can horizontal resistance be recognized in the presence of vertical resistance in plants exposed to a mixture of pathogen races? The American Phytopathological Society, Saint Paul, v.73, n.3, p. 379, 1983.

14. Pierozzi, P.H.B.; Ribeiro,A.S.; Moreira, J.U.V.; Laperuta, L. D.C.; Rachid, B.F.; Lima, W.F.; Arias, C.A.A.; Oliveira, M.F.; Toledo, J.F.F. New soybean (Glycine Max Fabales, Fabaceae) sources of qualitative genetic resistance to Asian soybean rust caused by Phakopsora pachyrhizi (Uredinales, Phakopsoraceae). Genetics and Molecular Biology, Ribeirão Preto, v.31, n.2, p. 505-511, 2008 .

15. Ribeiro, A.S.; Toledo, J.F.F.; Ramalho, M.A.P. Selection strategi- es of segregante soybean populations for resistance to Asian rust. Pesquisa Agropecuária Brasileira, Brasília, v.44, n.11, p.1452-1459, nov. 2009

16. Ribeiro, A.S.; Toledo, J.F.F.; Ramalho, M.A.P. Interference of genotypes $\mathrm{x}$ environments interation in the genetic control of resistance to Asian rust soybean. Pesquisa Agropecuária Brasileira, Brasília, v.44, n.9, p.1160-1167, set. 2009.

17. Ribeiro, A.S.; Moreira, J.U.V.; Pierozzi, P.H.B.; Rachid, B.F.; Toledo, J.F.F.; Arias, C.A.A.; Soares, R. M.; Godoy, C.V. Genetic control of Asian rust in soybean. Euphytica, Dordrecht, v. 157, n. $1-2$, p. 15-25, 2007

18. Robinson, R.A. Disease resistance terminology. Review of Applied Mycology, Surrey, v.48, p. 593-606, 1969.

19. SAS INSTITUTE (Cary, Estados Unidos). SAS/STAT user's guide: statistics. 5th ed. Cary, 1990. 1686 p.

20. Sinclair, J.B.; Hartman, G.L.; Management of soybean rust. In: Soybean Rust Workshop,1995, Urbana. Proceedings... Urbana: College of Agricultural, Consumer and Enviromental Sciences, National Soybean Research Laboratory, 1995. p. 6-10.

21. Tschanz, A.T.; Wang, T.C. Interrelationship between soybean development, resistance, and Phakopsora pachyrhizi. Soybean Rust Newsletter, Shanhua, v. 8, p. 14-20, Jun. 1987.

22. United States Department of Agriculture. Disponível em : <http:/ /www.fas.usda.gov/psdonline/psdQuery.aspx >. Acesso em: 18 abr. 2011.

23. Vanderplank, J.E. Disease resistance in plants. New York, Academic Press, 1968. 206 p.

24. Vello, N.A.; Brogin, R.L.; Arias, C.A.A. Estratégias de melhoramento para o controle da ferrugem da soja. In: Congresso Brasileiro de Soja e Mercosoja, 2., 2002. Londrina. Anais... Londrina: Embrapa Soja, 2002. p. 188-196.

25. Yorinori, J.T.; Paiva, W. M.; Frederick, R.D.; Costamilan, L.M.; Bertagnolli, P.F. Epidemia da ferrugem da soja (Phakopsora pachyrhizi) no Brasil e no Paraguai, em safras 2001 e 2002. Fitopatologia Brasileira, Brasília, DF, v.27, suplemento, p. 178-179, 2002.

26. Yorinori, J.T.; Nunes Junior, J.; Lazzarotto, J.J. Ferrugem "asiática" da soja no Brasil: evolução, importância econômica e controle. Londrina: Embrapa Soja, 2004. 36 p. (Embrapa Soja. Documentos, 204). 